\title{
Damage Zone Size Limit During the Crack Propagation
}

\author{
Hamid Hamli Benzahar ${ }^{1 *}$, Mohamed Chabaat² \\ ${ }^{1}$ Department of Civil and Mechanical Engineering, Faculty of Technology University Djillali Bounaama Khemis Miliana, Route de \\ Theniet El-Had, 44225, Algeria \\ 2 Department of Structures and Materials, Civil Engineering. Faculty, University of Sciences and Technology Houari Boumediene, \\ B.P. 32 El-Alia, Bab Ezzouar, Algiers, 16111, Algeria \\ *Corresponding author, e-mail: hamli-zahar@univ-dbkm.dz
}

Received: 26 July 2019, Accepted: 31 October 2019, Published online: 08 January 2020

\begin{abstract}
The principal goal of this work is to limit the damage zone length during the crack propagation in brittle materials. This study is based on the determination of stress fields by varying the distance between a semi-infinite crack and a neighboring dislocation. The model suggested is a rectangular element (a dish), having a semi-infinite crack in one of its ends and a dislocation located in the vicinity of a crack-tip, subjected to a tensile stress on mode I. The problem is treated numerically using Finite Element Method.For each distance between the two cracks (semi-infinite crack and dislocation), stress fields are given. On the basis of these stress fields, a limiting damage zone length is obtained.
\end{abstract}

\section{Keywords}

dislocation, semi-infinite crack, stress, propagation, damage zone

\section{Introduction}

The area found at the edge of a semi-infinite crack in a brittle material is given by shapes that can't be determined by classical elasticity approaches [1,2]. This area, known as a Damage Zone (DZ) or sometimes as a Process Zone (PS), can be defined like a sector of stress field's concentrations. These latest are obtained using exact analytical methods for some particular cases and analytical approximations in certain claims. DZ can be limited in the presence of dislocations nearby the edge crack-tip [3]. In this research work, we consider only one dislocation interacting with a main crack and by varying the distance as well as the angular orientation between the dislocation and the edge crack-tip, the stress field $\left(\sigma_{11}, \sigma_{12}, \sigma_{22}\right)$ are obtained. In our case, a finite element which is a brittle material having a rectangular form is chosen. It has a length $(L=70 \mathrm{~cm})$, a width $(d=50 \mathrm{~cm})$ and a thickness $(e=2 \mathrm{~mm})$ with a semi-infinite edge crack surrounded by a moving dislocation. A remote loading is applied according to the first mode I. The model is discretized with finite elements of square and triangular form. On the basis of these stress fields, a limiting DZ length is obtained.

\section{Zones around the semi-infinite crack}

According to the first mode of fracture [4], in a fissured medium and from a mechanical point of view, one disting- uishes three consecutive zones (Fig. 1). Firstzone (zone I; the damage zone): The study of this zone is very difficult, because the stress field distribution in this zone are very high and disturbing.Second zone (zone II; the singular zone): The stress and displacements fields are continuous. In this zone, the components of the strains and stress fields are infinite with the proximity of the semi-infinite crack. Third zone (zone III; the external zone), in which one can determine the fields of stress, deformation and displacements while applying the boundary conditions.

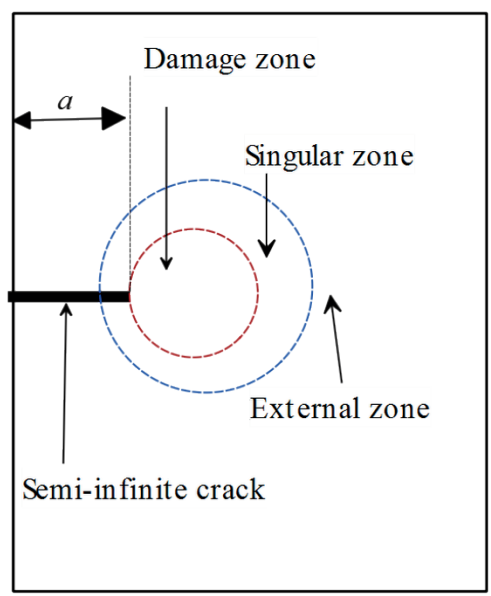

Fig. 1 Zones created at the edge of a semi-infinite crack 


\subsection{Stress distribution}

In linear behavior, the theory of elasticity is employed to characterize the state of stress and displacement at the neighborhood of a semi-infinite crack [5]. Thus, the stress distribution under the mode I traction is given by Chen [6]:

$$
\begin{aligned}
& {\left[\begin{array}{ll}
\sigma_{11} & \sigma_{12} \\
\sigma_{21} & \sigma_{22}
\end{array}\right]=\frac{\mathrm{K}_{\mathrm{I}}}{\sqrt{2 \pi r}}\left[\begin{array}{ll}
f_{11}(\theta) & f_{12}(\theta) \\
f_{21}(\theta) f_{22}(\theta)
\end{array}\right]} \\
& +\frac{\mathrm{K}_{\mathrm{II}}}{\sqrt{2 \pi r}}\left[\begin{array}{ll}
\mathrm{g}_{11}(\theta) & \mathrm{g}_{12}(\theta) \\
\mathrm{g}_{21}(\theta) & \mathrm{g}_{22}(\theta)
\end{array}\right],
\end{aligned}
$$

where $\sigma_{i j}$ is the plane stress, $\mathrm{K}_{\mathrm{I}}$ and $\mathrm{K}_{\mathrm{II}}$ correspond to the stress intensity factor under the effect of the first and second mode respectively, $r$ is the distance between the DZ and the tip of the semi-infinite crack. $f_{i j}(\theta)$ and $g_{i j}(\theta)$ are the angular functions of distribution of the stresses in the vicinity of a semi-infinite crack [7].

\subsection{Dislocations}

Dislocations or microcracks are crystalline defects and are easily detected by an electronics device such as a high resolution microscope $[8,9]$. These defects can affect the macro crack by amplifying or reducing the stress field around a crak-tip. This phenomena can lead us to an acceleration of the a crack or toward a crack arrest. Generally, each dislocation is endowed with a force of action generated by the displacement of the atoms and their interactions [10]. The dislocation movement follows a translation vector noted $b$ and called Burgers vector [11], given by the following expression;

$$
b=b_{x}+b_{y} .
$$

Consequently, there are three types of dislocations as a function of the position of the burger vector $b$ with respect to the dislocation line denoted $L$ (see Fig. 2);

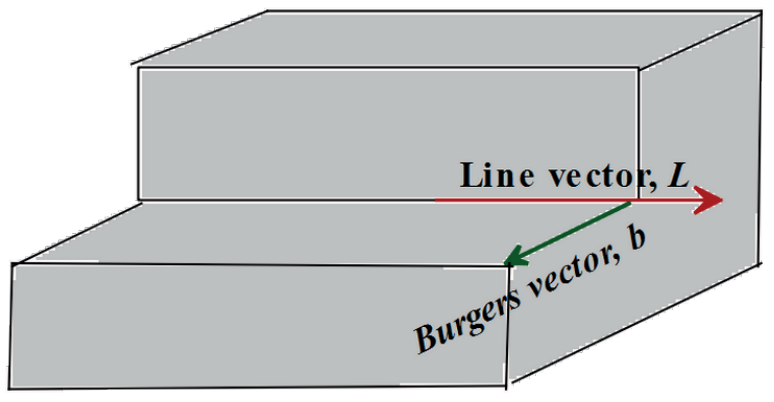

Fig. 2 Presentation of a dislocation
The dislocation is called screw if the burger vector is parallel to the line vector $(b / / L)$. This dislocation is called edge if the burger vector is perpendicular to the line vector $(b \perp L)$. If $b$ is arbitrary then the dislocation is mixed and the angle between $b$ and $L$ is called the dislocation character [12].

The complex analytical functions of a dislocation are given by the following relation:

$\phi_{d}=\gamma \ln \left(z-z_{d}\right)$,

$\psi_{d}=\bar{\gamma} \ln \left(z-z_{d}\right)-\gamma\left[z_{d} /\left(z-z_{d}\right)\right]$,

with;

$\gamma=\mu b /[i \pi(k+1)]$,

and where;

$\psi_{d}$ and $\phi_{d}$ are the complex analytical functions of dislocation,

$b_{e}$ is the burger vector,

$Z$ is the complex number,

$\bar{\gamma}$ and $\bar{z}$ are the conjugate of $\gamma$ and $z$, respectively,

$v$ is the Poisson's ratio.

In case of a plane stress, the coefficient $k$ is given as a function of Poisson's ratio such as;

$k=3-4 v$.

\section{Fracture modes}

The crack propagation can generate three modes of fracture explained by the displacement of internal faces of the crack $[13,14]$. The first mode (Mode I) is an opening mode from which faces move perpendicular to the plane of the crack. The second mode (Mode II) is a right sliding of the faces in a direction perpendicular to the crack front. The displacement of the internal faces in the same plane and in a direction parallel to the crack front, defined by a third screw sliding mode (Mode III). The Fig. 3 shows the three modes of fracture [15].

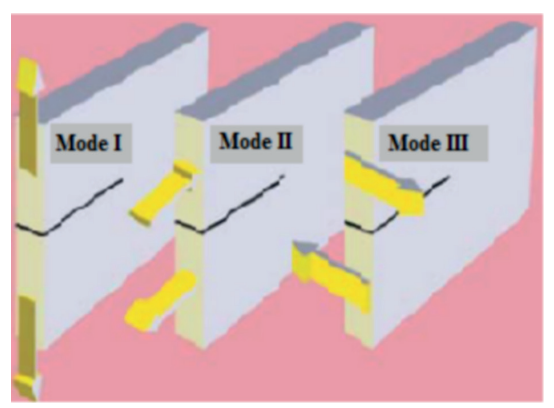

Fig. 3 Fracture modes 


\section{Semi-infinite crack-damage interaction}

The general formulation of a problem of interaction implies a propagation of a semi-infinite crack in a neighbouring zone called damage zone or process zone [16, 17]. The stress and displacements components of a dislocation near the semi-infinite crack are formulated by employing the complexes potentials theory of the elasticity of Muskhelishvili [18]. The elastic behavior of the cracks has been studied by a large number of researchers [19, 20]. The stress fields generated during the interaction between a semi-infinite crack and a neighboring dislocation are formulated as follows [21];

$$
\left\{\begin{array}{l}
\sigma_{11} \\
\sigma_{22} \\
\sigma_{12}
\end{array}\right\}=\frac{2 \mu b \cos (\theta)}{\pi(k+1) l}\left\{\begin{array}{c}
3-\sin (2 \theta) \tan (\theta) \\
1+\sin (2 \theta) \tan (\theta) \\
-2\left[\sin ^{2} \theta \tan (\theta)+1\right]
\end{array}\right\},
$$

where $b$ is the burgers vector. $l$ is the distance between dislocation and the semi-infinite crack. $\theta$ is the orientation angle of the dislocation around itself.

\section{Numerical analysis}

The proposed model is an element of brittle material (glass) of rectangular shape cracked at the end (see Fig. 4), has a length $H=700 \mathrm{~mm}$, a width $B=500 \mathrm{~mm}$ and a thickness $t=2 \mathrm{~mm}$. Thus, there is a dislocation of circular shape having a diameter $d_{0}=0.5 \mathrm{~mm}$ (that is to say $b_{y}=b_{x}=0.1 \mathrm{~mm}$ ), varies in the vicinity of the semi-infinite crack according to the distance $d$.

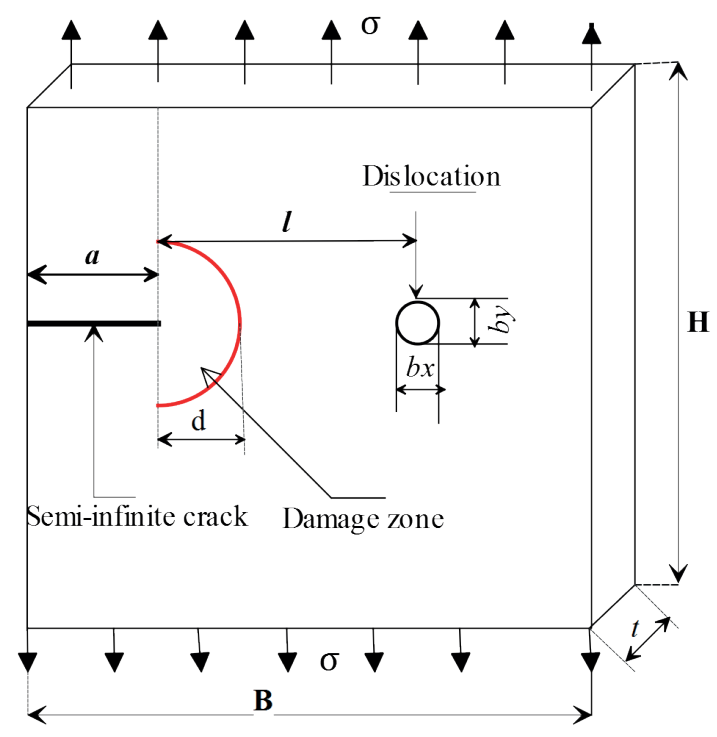

Fig. 4 Presence of a dislocation nearby a semi-infinite crack

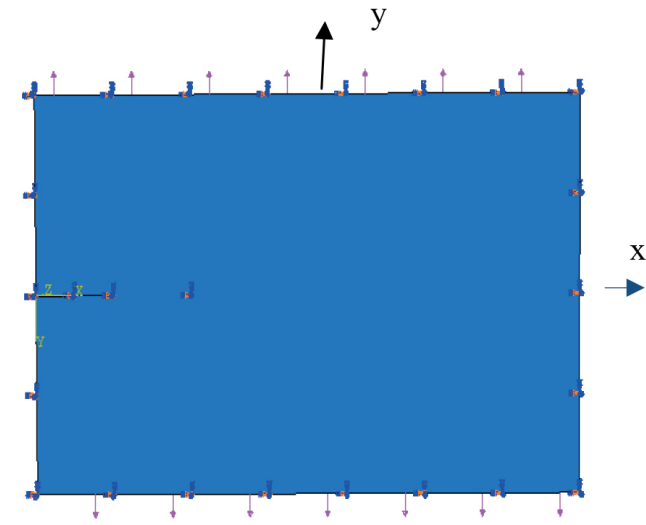

Fig. 5 System of loading according to a mode I

The problem is studied using a numerical approach based on the finite element method using ABAQUS. The material used in this study has a heterogeneous brittle behavior whose elasticity modulus is equivalent to $E=72000 \mathrm{~N} / \mathrm{mm}^{2}$ and the Poisson's ratio $v=0.25$ which corresponds to a glass [22]. Taking account the boundary conditions, the loading is applied according to the y-axis, that is to say the opening of the semi-infinite crack will be perpendicular to the $\mathrm{x}$-axis (mode I), the Fig. 5 shows the loading and the opening mode of the crack.

By varying the length of the semi-infinite crack $(a)$ and the distance between semi-infinite crack and dislocating $(d)$, all the plane stresses will be determined. The following cartograms represent the maximum stresses $\left(\sigma_{22}, \sigma_{11}\right)$.

According to the Fig. 6 and Fig. 7, stress values are increasingly higher at the end of the semi-infinite crack and other negative in the free zone. The Table 1 gives all the stress values found using different lengths of a semiinfinite crack while varying the distance between the crack and the dislocation.

The values given in Table laredrawn as curves in Figs. 8 to 12 . These curves represent the variation of stress as a function of the distance between a crack and a nearby dislocation for each length of the semi-infinite crack.

\section{Stress intensity factor SIF}

Numerical or theoretical constraints found are characterized by the stress intensity factor (SIF), a crucial parameter for determining the breaking strength of a material $[23,24]$. SIF representing the mode I and II are given by the following relation;

$k_{1}-i k_{2}=\lim _{z \rightarrow 0} \sqrt{2 \pi z}\left(\sigma_{22}-\sigma_{12}\right)$,

with; $k_{1}$ an $k_{2}$ are the stress intensity factor in mode I and mode II, respectively, $z$ is a complex number and $i$ represents the imaginary part. 

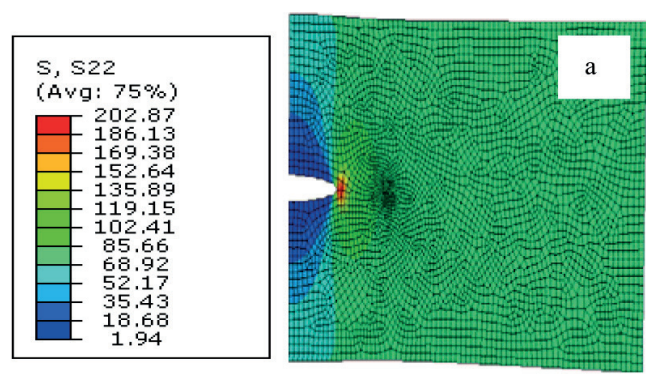

(a)
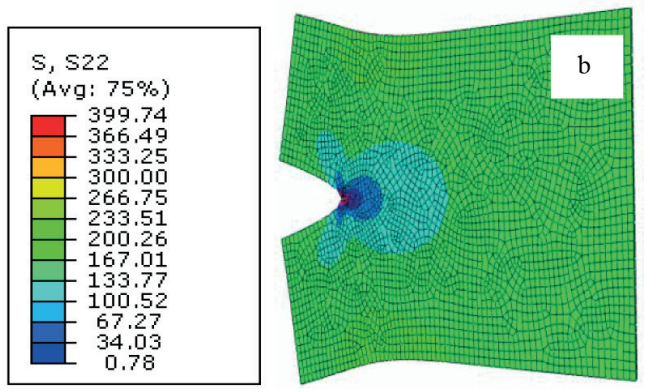

(b)
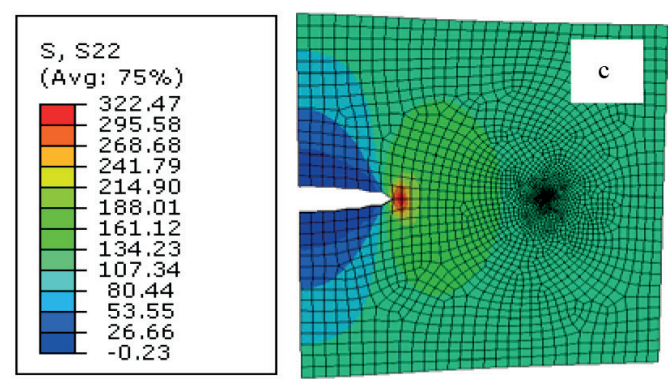

(c)
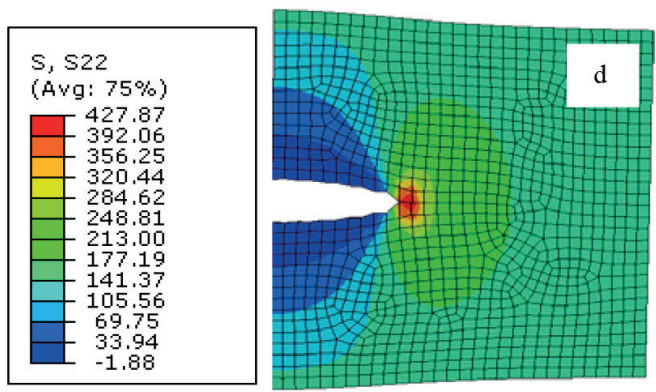

(d)
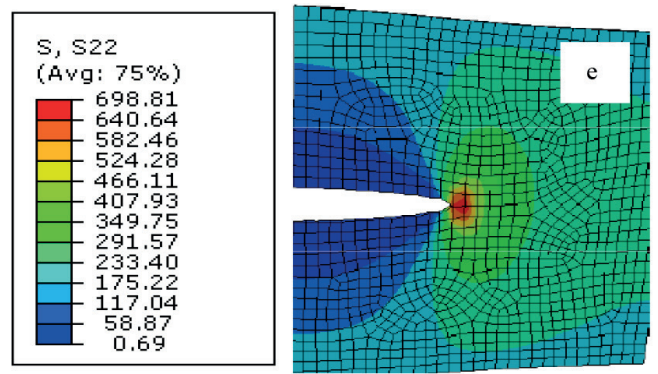

(e)

Fig. 6 Constraints along the $y-y$ direction $\left[\sigma_{22}\left(\mathrm{daN} / \mathrm{cm}^{2}\right)\right]$, cases: a) $=50 \mathrm{~mm}, \mathrm{~b}) a=100 \mathrm{~mm}, \mathrm{c}) a=150 \mathrm{~mm}, \mathrm{~d}) a=200 \mathrm{~mm}, \mathrm{c}) \mathrm{a}=250 \mathrm{~mm}$
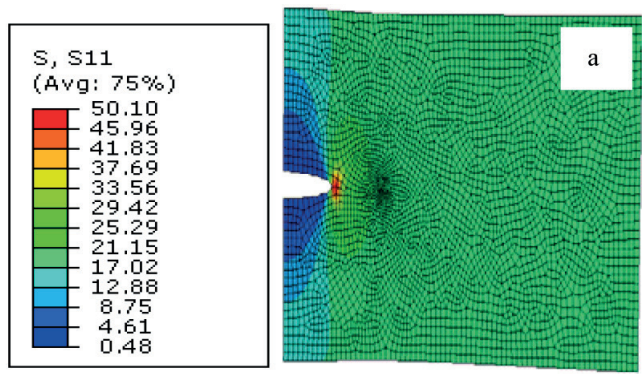

(a)
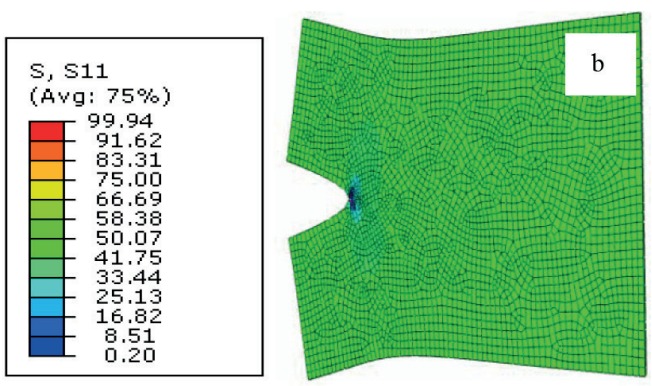

(b)
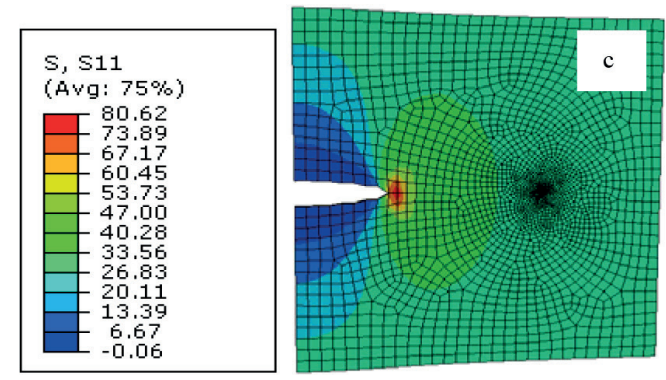

(c)
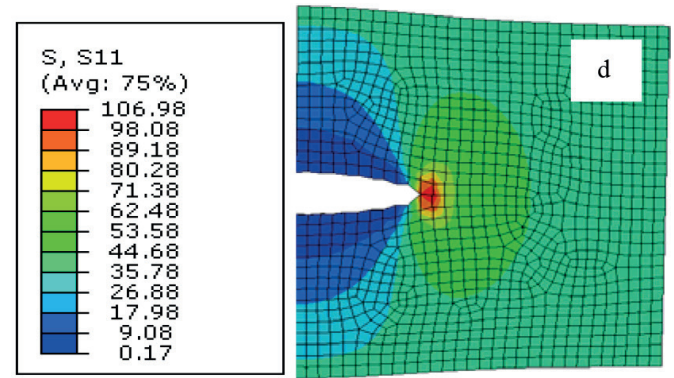

(d)
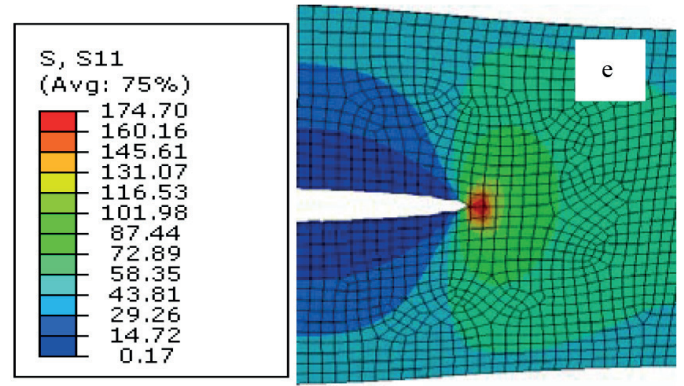

(e)

Fig. 7 Constraints along the $\mathrm{x}-\mathrm{x}$ direction $\left[\sigma_{11}\left(\mathrm{daN} / \mathrm{cm}^{2}\right)\right]$, cases: a) $\mathrm{a}=50 \mathrm{~mm}, \mathrm{~b}) \mathrm{a}=100 \mathrm{~mm}, \mathrm{c}) \mathrm{a}=150 \mathrm{~mm}, \mathrm{~d}$ ) a $=200 \mathrm{~mm}, \mathrm{e}) \mathrm{a}=250 \mathrm{~mm}$ 
Table 1 Stress values for several crack lengths $(a)$ with different distances between crack-dislocation $(l)$

\begin{tabular}{|c|c|c|c|c|}
\hline$a(\mathrm{~mm})$ & $d(\mathrm{~mm})$ & $\sigma_{22}$ & $\sigma_{11}$ & $\sigma_{12}$ \\
\hline \multirow{6}{*}{50} & 1 & 148.44 & 37.11 & 47.28 \\
\hline & 5 & 124.79 & 31.2 & 40.06 \\
\hline & 10 & 110.62 & 27.66 & 41.53 \\
\hline & 20 & 73.97 & 18.49 & 41.68 \\
\hline & 50 & 68.00 & 16.00 & 21.87 \\
\hline & 100 & 60.26 & 15.07 & 20.00 \\
\hline \multirow{6}{*}{100} & 1 & 398.45 & 94.11 & 178.10 \\
\hline & 5 & 405.05 & 65.75 & 72.88 \\
\hline & 10 & 273.79 & 39.44 & 63.57 \\
\hline & 20 & 153.67 & 47.86 & 70.06 \\
\hline & 50 & 146.71 & 39.44 & 63.57 \\
\hline & 100 & 129.98 & 21.01 & 62.41 \\
\hline \multirow{6}{*}{150} & 1 & 409.28 & 102.32 & 124.76 \\
\hline & 5 & 380.00 & 97.00 & 101.00 \\
\hline & 10 & 194.34 & 48.59 & 105.79 \\
\hline & 20 & 144.8 & 47.16 & 63.52 \\
\hline & 50 & 116.9 & 29.23 & 84.72 \\
\hline & 100 & 110.00 & 26.00 & 79.00 \\
\hline \multirow{6}{*}{200} & 1 & 427.92 & 106.98 & 123.77 \\
\hline & 5 & 317.19 & 79.30 & 116.92 \\
\hline & 10 & 332.31 & 83.08 & 113.64 \\
\hline & 20 & 181.08 & 45.27 & 115.09 \\
\hline & 50 & 160.00 & 40.00 & 112.00 \\
\hline & 100 & 141.17 & 35.29 & 110.94 \\
\hline \multirow{6}{*}{250} & 1 & 698.91 & 174.7 & 187.76 \\
\hline & 5 & 500.67 & 125.17 & 140.84 \\
\hline & 10 & 348.48 & 87.12 & 139.51 \\
\hline & 20 & 207.10 & 51.78 & 135.25 \\
\hline & 50 & 186.82 & 46.70 & 123.98 \\
\hline & 100 & 161.62 & 40.40 & 135.25 \\
\hline
\end{tabular}

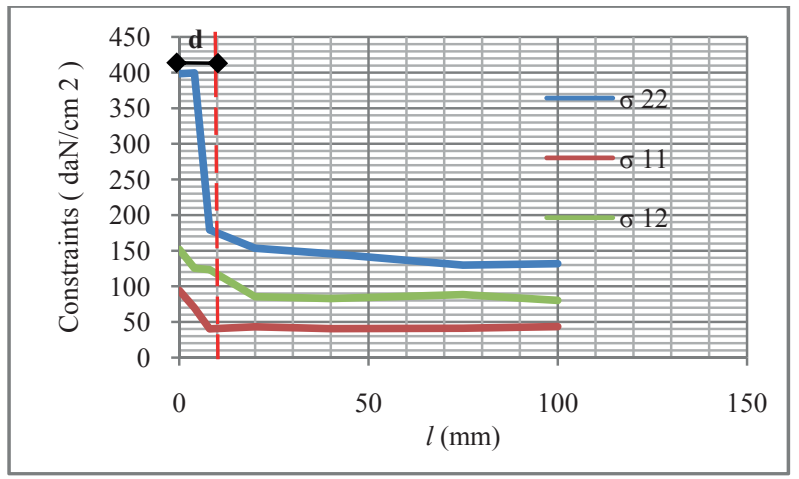

Fig. 8 Variation of constraints vs.the distance $(l)$ between a semiinfinite crack and a surrounding dislocation (case: $\mathrm{a}=50 \mathrm{~mm}$ )

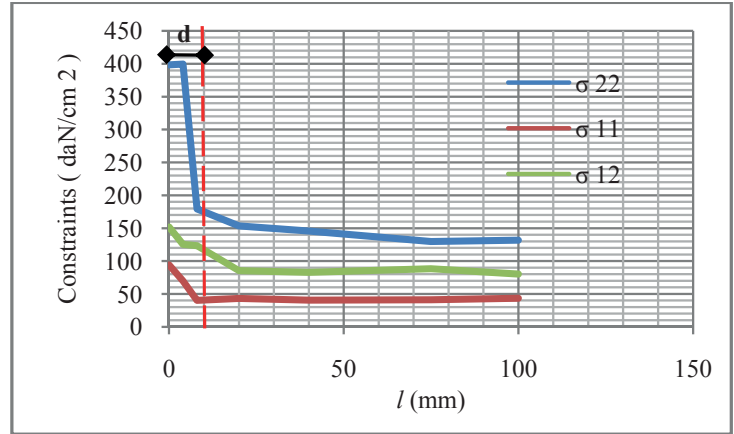

Fig. 9 Variation of constraints vs. the distance $(l)$ between a semiinfinite crack and a surrounding dislocation (case: $\mathrm{a}=100 \mathrm{~mm}$ )

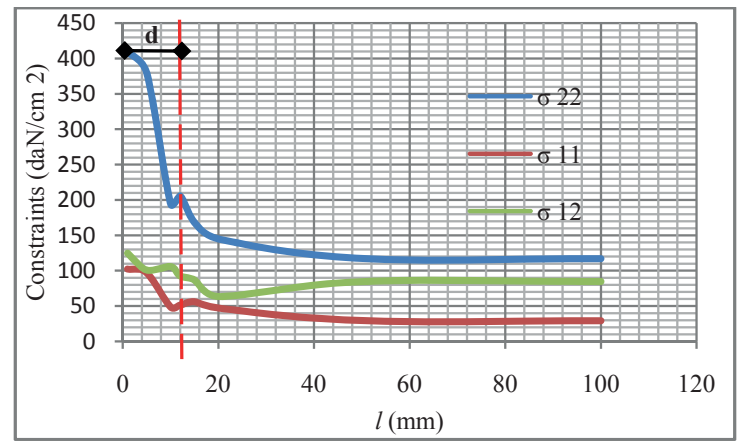

Fig. 10 Variation of constraints vs. the distance $(l)$ between a semiinfinite crack and a surrounding dislocation (case: $=150 \mathrm{~mm}$ )

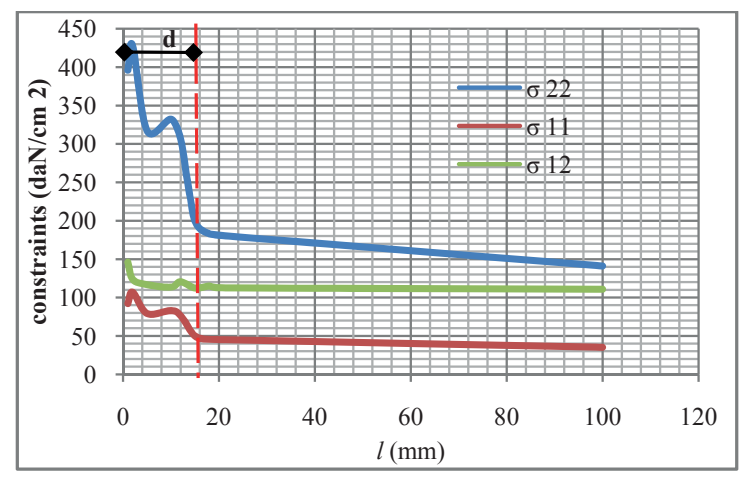

Fig. 11 Variation ofconstraints vs. the distance $(l)$ between a semiinfinite crack and a surrounding dislocation (case: $\mathrm{a}=200 \mathrm{~mm}$ )

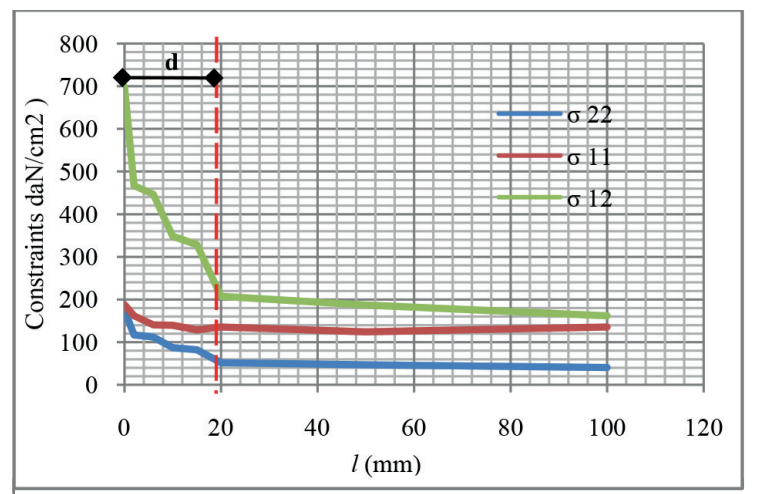

Fig. 12 Variation ofconstraintsvs. the distance $(l)$ between a semiinfinite crack and a surrounding dislocation (case: $\mathrm{a}=250 \mathrm{~mm}$ ) 


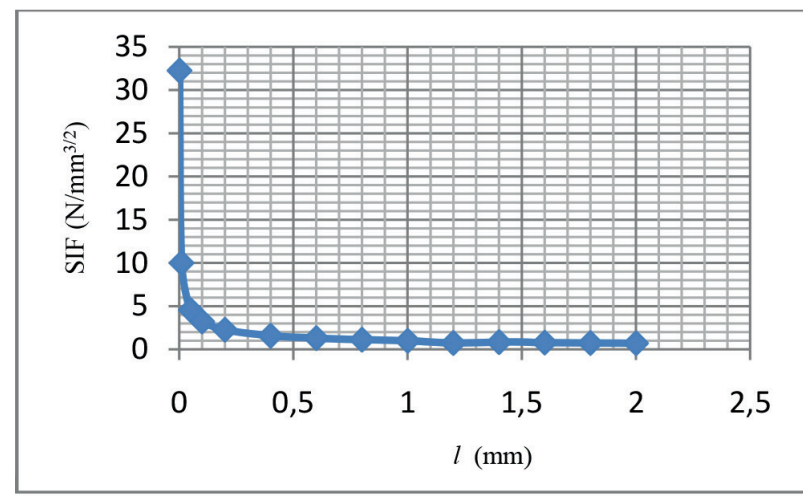

Fig. 13 Variation of SIF vs. the distance $(l)$ between a semi-infinite crack and a surrounding dislocation

In our case, the dislocation is perpendicular to the semiinfinite crack $(\theta=3 \pi / 2)$. Substituting Eq. (7) into Eq. (8) and separating the real part from the imaginary part, SIF in a mode I takes the following form;

$k_{1}=\frac{5 \sqrt{2} \mu b}{\sqrt{\pi l}(k+1)}$.

In Fig. 13, the variation of the SIF versus a function of the distance between the dislocation and a semi-infinite crack is represented.

\section{Discussions and analysis}

In this research, stressare given during the propagation of a crack in a brittle material (a glass) and are represented in Fig. 6 and Fig. 7. Depending onthe distance between adislocation and a semi-infinite $\operatorname{crack}(l)$, the stress field $\left(\sigma_{22}, \sigma_{11}, \sigma_{12}\right)$ vary at the same ratio (see Figs. 8 to 12$)$.

The constraint $\sigma_{22}$ is parallel to the loading serving the opening according to the first mode of fracture (mode I). In all cases, we notice that the constraint $\sigma_{22}$ is the highest than the other two constraints $\left(\sigma_{11}, \sigma_{12}\right)$.

Fig. 8 represents the variation of the stress field function of the distance $(l)$ between the dislocation and the semi-infinite crack. The length of the semi-infinite crack is taken $a=50 \mathrm{~mm}$, the main remark is that the stress field change their rate increasingly from the distance $d \epsilon] 0,4] \mathrm{mm}$.

In Fig. 9, the length of the semi-infinite crack is chosen to be $a=100 \mathrm{~mm}$. For a given distance $(d)$ between a nearby dislocation and a crack-tip $d \epsilon] 0,8] \mathrm{mm}$, stress values start to rise in an exponential form.

In Fig. 10, the stress fields represented as curves, reach maximum values for $d \epsilon] 0,12] \mathrm{mm}$, the same remark can be made in Fig. 11 and Fig. 12 for the stress field reaching higher values for $d \epsilon] 0,16] \mathrm{mm}$ and for, respectively.
On the basis of the stress field values obtained in Figs. 7 and 8, varying the length $(a)$ of the semi-infinite crack and the distance $(l)$ between the semi-infinite crack and a nearby dislocation, we notice, for each case, there are very high stress generated when the dislocation approaches the crack-tipfrom a short distance noted $d$ and considered as being the length of the DZ. The ratio $(R)$ of two lengths ( $a$; length of the damage zone and $d$; length of the semiinfinite crack) is given by the following expression:

$R(\%)=[d / a] \times 100$,

where $d$ is the distance between the dislocation and the main crack and a is the length of the semi-infinite crack.

$R(\%)$ is the percentagelength of DZ with respect to the semi infinite crack length.

Obtained results for each case (see Figs. 8 to 12) are summarized in the Table 2.

From the Table 2, we can deduce that the length of the $\mathrm{DZ}$ is about eight percent ( $8 \%$ ) of the length for the five cases. It is also noticed that a deep analysis of the stress field with the corresponding distance between the main crack and the dislocation lead us to the same ratio of $8 \%$ of the crack length. This \% is quiet obvious since the DZ is considered as being very small in comparaison to the crack length as well as to the specimen dimension.

\section{Conclusions}

In this research work, the principal objective is to limit the length of the damage zone with respect to the main crack.

Table 2 Percentage of the DZ length compared to the semi-infinite crack length

\begin{tabular}{|c|c|c|c|c|c|}
\hline Figures & $a(\mathrm{~mm})$ & $\sigma_{i j}\left(\mathrm{daN} / \mathrm{cm}^{2}\right)$ & $d(\mathrm{~mm})$ & $d / a$ & $R(\%)$ \\
\hline \multirow{3}{*}{ Fig. 8} & \multirow{3}{*}{50} & $\sigma_{11}$ & 4 & 0.08 & 8 \\
\hline & & $\sigma_{12}$ & 4 & 0.08 & 8 \\
\hline & & $\sigma_{22}$ & 4 & 0.08 & 8 \\
\hline \multirow{3}{*}{ Fig. 9} & \multirow{3}{*}{100} & $\sigma_{11}$ & 8 & 0.08 & 8 \\
\hline & & $\sigma_{12}$ & 8 & 0.08 & 8 \\
\hline & & $\sigma_{22}$ & 8 & 0.08 & 8 \\
\hline \multirow{3}{*}{ Fig. 10} & \multirow{3}{*}{150} & $\sigma_{11}$ & 12 & 0.08 & 8 \\
\hline & & $\sigma_{12}$ & 18 & 0.12 & 12 \\
\hline & & $\sigma_{22}$ & 12 & 0.08 & 8 \\
\hline \multirow{3}{*}{ Fig. 11} & \multirow{3}{*}{200} & $\sigma_{11}$ & 16 & 0.08 & 8 \\
\hline & & $\sigma_{12}$ & 4 & 0.02 & 2 \\
\hline & & $\sigma_{22}$ & 16 & 0.08 & 8 \\
\hline \multirow{3}{*}{ Fig. 12} & \multirow{3}{*}{250} & $\sigma_{11}$ & 20 & 0.08 & 8 \\
\hline & & $\sigma_{12}$ & 6 & 0.024 & 2.4 \\
\hline & & $\sigma_{22}$ & 20 & 0.08 & 8 \\
\hline
\end{tabular}


The so called damage zone can be detected by the presence of defects (dislocations, micro-cracks...). In changing the distance between the dislocation and the main edge semi-infinite crack, stress fields reach high values once closerto the crack-tip and get weak values once the dislocation is far away from the crack-tip. It is shown that this phenomena is generatedby two effects: amplification and

\section{References}

[1] Liu, X., Duddu, R.,Waisman, H. "Discrete damage zone model for fracture initiation and propagation", Engineering Fracture Mechanics, 92, pp. 1-18, 2012.

https://doi.org/10.1016/j.engfracmech.2012.04.019

[2] Kosteski, L., Iturrioz, I., Batista, R. G., Cisilino, A. P. "The trusslike discrete element method in fracture and damage mechanics", Engineering Computations, 28(6), pp. 765-787, 2011. https://doi.org/10.1108/02644401111154664

[3] Shih, C. F., Asaro, R. J. "Elastic-Plastic Analysis of Cracks on Bimaterial Interfaces: Part I - Small Scale Yielding", Journal of Applied Mechanics, 55(2), pp. 299-316, 1988.

https://doi.org/10.1115/1.3173676

[4] Hadei, M. R., Kemeny, J., Ghazvinian, A., Rezaiepoor, A., Sarfarazi, V. "New Development to Measure Mode I. Fracture Toughness in Rock", Periodica Polytechnica Civil Engineering, 61(1), pp. 51-55, 2017. https://doi.org/10.3311/PPci.9264

[5] Chabaat, M. "Comparison of minimal principal stress trajectories with craze distribution in an amorphous polymer", International Journal of Fracture, 37(4), pp. R47-R54, 1988.

https://doi.org/10.1007/BF00032536

[6] Chen, Y. Z., Lin, X. Y., Wang, Z. X. "A rigorous derivation for T-stress in line crack problem", Engineering Fracture Mechanics, 77(4), pp. 753-757, 2010.

https://doi.org/10.1016/j.engfracmech.2009.11.008

[7] Chen, Y. Z., Wang, X. Z., Lin, X. Y. "Crack front position and crack back position techniques for evaluating the T-stress at crack tip using functions of a complex variable", Journal of Mechanics of Materials and Structures, 3(9), pp. 1659-1673, 2008.

https://doi.org/10.2140/jomms.2008.3.1659

[8] Hadjab-Souag, H., Thimus, J.-F., Chabaat, M. "Detecting the fracture process zone in concrete using scanning electron microscopy and numerical modelling using the nonlocal isotropic damage model", Canadian Journal of Civil Engineering, 34(4), pp. 496-504, 2007.

https://doi.org/10.1139/106-132

[9] Penisson, J. M. "Analysis of the Structure and Chemistry of Crystalline Defects by Tem", In: Lépinoux, J., Maziére, D., Pontikis, V., Saada, G. (eds.) Multiscale Phenomena in Plasticity: From Experiments to Phenomenology, Modelling and Materials Engineering, Springer, Dordrecht, Netherlands, 2000, pp. 195-204. https://doi.org/10.1007/978-94-011-4048-5_15 shielding effects. Besides, it is noticed in this study that all stress fields vary at the same rate with respect to the distance $d$ and they increase in an exponential way once the dislocation gets closer to the semi-edge crack-tip. Based on stress analysis,the length of the $\mathrm{DZ}$ is found to be equal toeight percent $(8 \%)$ of the overall length of the semi-infinite edge crack.

[10] Chudnovsky, A., Wu, S. "Elastic interaction of a crack with a random array of microcracks", International Journal of Fracture, 49(2), pp. 123-140, 1991.

https://link.springer.com/article/10.1007/BF00039775

[11] Mughrabi, H. "Dislocation clustering and long-range internal stresses in monotonically and cyclically deformed metal crystals", Revue de Physique Appliquée, 23(4), pp. 367-379, 1988. https://doi.org/10.1051/rphysap:01988002304036700

[12] Kratochvil, J. "Dislocation pattern formation in metals", Revue de Physique Appliquée, 23(4), pp. 419-429, 1988. https://oi.org/10.1051/rphysap:01988002304041900

[13] Ahmadi, M. H., Molladavoodi, H. "A Micromechanical SlidingDamage Model Under Dynamic Compressive Loading", Periodica Polytechnica Civil Engineering, 63(1), pp. 168-183, 2019. https://doi.org/10.3311/PPci.13249

[14] Rizov, V. "Analysis of mixed-mode II/III fracture in sandwich beams", Multidiscipline Modeling Materials and Structures, 11(1), pp. 75-87, 2015. https://doi.org/10.1108/MMMS-06-2014-0034

[15] Ravi-Chandar, K., Knauss, W. "Processes controlling fast fracture of brittle solids", Computing in Science \& Engineering, 1(5), pp. 24-31, 1999. https://doi.org/10.1109/5992.790584

[16] Ayas, H., Hamli Benzahar, H., Chabaat, M. "Energy Release Rate During the Cracking of Composite Materials", Energy Procedia, 74, pp. 1040-1047, 2015. https://doi.org/10.1016/j.egypro.2015.07.742

[17] Ying, Z., Yuji, T. "Spectral Method for Fatigue Damage Assessment of Structures with Uncertain Parameters", Periodica Polytechnica Civil Engineering, 61(4), pp. 929-938, 2017. https://doi.org/10.3311/PPci.9644

[18] Mushkelishvili, N. I. "Basic Equations of the Plane Theory of Elasticity", In: Some Basic Problems of the Mathematical Theory of Elasticity, Springer, Dordrecht, Netherlands, 1977, pp. 89-104. https://doi.org/10.1007/978-94-017-3034-1_4

[19] Lan, X., Shaobo, J., Noda, N.-A., Cheng, Y. "The Effect of Geometric Configurations on the Elastic Behavior of an Edge-Cracked Bonded Strip", Advances in Materials Science and Engineering, 2017, Article ID: 2380740, 2017. https://doi.org/10.1155/2017/2380740

[20] Walsh, J. B. "The effect of cracks in rocks on Poisson's ratio", Journal of Geophysical Research, 70(20), pp. 5249-5257, 1965. https://doi.org/10.1029/JZ070i020p05249 
[21] Hamli Benzahar, H. "Theoretical and numerical analysis of stress and stress intensity factor in bi-material", International Journal of Structural Integrity, 10(1), pp. 76-84, 2019. https://doi.org/10.1108/IJSI-08-2018-0048

[22] Hamli Benzahar, H., Chabaat, M. "Crack in a Brittle Material at the Presence of a Dislocation", Advanced Material Research, 919-921, pp. 2043-2047, 2014.

https://doi.org/10.4028/www.scientific.net/AMR.919-921.2043
[23] Zhang, T.-Y., Li, J. C. M. "Interaction of an edge dislocation with an interfacial crack", Journal of Applied Physics, 72(6), pp. 22152226, 1992.

https://doi.org/10.1063/1.351614

[24] Zhang, Y., Qiao, P. "A new bond failure criterion for ordinary statebased peridynamic mode II fracture analysis", International Journal of Fracture, 215(1-2), pp. 105-128, 2019.

https://doi.org/10.1007/s10704-018-00341-x 